\title{
ARTIKELEN
}

\section{Een discipline in transitie}

\section{Rechtswetenschappelijk onderzoek na de Commissie Koers*}

\author{
Carel Stolker
}

In 2010 verscheen het rapport Kwaliteit \& diversiteit van de Commissie Koers die het wetenschappelijk onderzoek van negen Nederlandse juridische faculteiten beoordeelde. De conclusie van het rapport is dat het 'goed' gaat met het rechtswetenschappelijk onderzoek in Nederland, maar tegelijkertijd ziet de Commissie 'een discipline in transitie'. De Commissie dringt er bij de decanen van de faculteiten op aan om veel meer te gaan samenwerken. Als uitgesproken 'zwak' benoemt ze het gegeven dat er binnen de discipline geen algemeen gedeelde opvatting bestaat over de wetenschappelijke kwaliteit op grond waarvan onderzoeksresultaten beoordeeld kunnen worden. In deze bijdrage blikt de auteur aan de hand van de bevindingen van de Commissie Koers terug en trekt hij lijnen naar de toekomst. Volgens hem verdient vooral de externe oriëntatie aandacht: de wetenschappelijke verantwoording (peer review, ranking, impactmeting), de steeds belangrijker wordende maatschappelijke verantwoording, en de thematisering van het juridische onderzoek (de Europese 'grand challenges' en de Nederlandse topsectoren).

\section{High trust en low trust}

Wij leven in een tijd van low trust in instituties die lang als high trust werden gezien. Voorbeelden zijn de rechterlijke macht en het hoger onderwijs; instituties van professionals, met een hoge mate van zeggenschap over de toegang tot de eigen professie, over de kwaliteit van het werk en over de organisatie ervan. Het vertrouwen van de samenleving was vanzelfsprekend. Maar die vanzelfsprekendheid lijkt af te nemen. De rechterlijke macht ligt onder vuur als gevolg van een aantal misslagen en onwennig manoeuvreren in de media. Een deel van het hoger onderwijs schudt op zijn fundamenten als gevolg van Inholland, en het wetenschappelijk onderzoek raakte in het defensief rond het VN-klimaatrapport. Hoewel het nog maar de vraag is of er ook patronen zijn aan te wijzen, lijkt de toon gezet. 'Ik luister eerder naar burgers dan naar de universiteit', merkte parlemen-

* $\quad$ Prof. dr. mr. Carel Stolker was decaan van de Faculteit der Rechtsgeleerdheid van de Universiteit Leiden. Daarvoor was hij vice-decaan voor het onderzoek en directeur van het facultaire E.M. Meijers Instituut. In het academisch jaar 2011-2012 werkt hij aan een boek over rechtenfaculteiten. De auteur dankt studentassistente Catherine Stip voor haar op intelligente wijze verzamelen van literatuur. Evenzeer dankt hij hen die eerdere versies van commentaar wilden voorzien. 
tariër Brinkman op naar aanleiding van datzelfde klimaatonderzoek. De affaire rond de Tilburgse hoogleraar Stapel zal koren op zijn molen zijn (Trouw 2011).

Wetenschap en rechterlijke macht kennen een eigen systeem om te reageren op fouten en onjuiste opvattingen. Wetenschap lééft van falsificatie door collegaonderzoekers (Popper 2003). Van Schoordijk zou de opdracht zijn die voor elke wetenschapper hoort te gelden: word het niet onnodig eens. In de rechtspraak is het de hogere rechter die tegenspel biedt. Daar bovenop is voor beide, academie en rechtspraak, het instrument van de visitatie ontwikkeld. Een team van peers bezoekt een organisatie eens in de zoveel jaar. Zij laten hun blik gaan over een gerecht, een onderzoeksgroep of een opleiding. Zij geven een oordeel over de bereikte kwaliteit, de omvang van de output, de mate waarin een organisatie haar doelen bereikt, de wijze waarop de interne kwaliteitszorg is geregeld en al dan niet wordt nageleefd, en voorts over alles waarover de professie of de samenleving een oordeel zouden willen hebben.

In deze bijdrage wordt een aantal observaties uit het visitatierapport Kwaliteit \& diversiteit van de Evaluatiecommissie Rechtswetenschappelijk Onderzoek 2009 (Commissie Koers) besproken en van commentaar voorzien. ${ }^{1}$ De Commissie beoordeelde het wetenschappelijk onderzoek van de negen Nederlandse rechtenfaculteiten aan de hand van door hen geschreven 'zelfstudies' en geselecteerde kernpublicaties. Op het niveau van de onderzoeksprogramma's keek de Commissie naar aspecten als de kwaliteit van het onderzoek, de productiviteit, de relevantie van het onderzoek en de vitaliteit (lees: de toekomst) ervan. Op een na, een lid uit Vlaanderen, bestond de Commissie uit Nederlanders.

Het oordeel van de Commissie Koers over de zestig (!) aan haar voorgelegde onderzoeksprogramma's was positief: 'Het gaat goed met het juridisch wetenschappelijk onderzoek in Nederland' (Commissie Koers 2010, p. 61). ${ }^{2}$ Er waren maar weinig afvallers. ${ }^{3}$ Dat is goed nieuws, ofschoon Pauline Westerman er terecht op wijst dat de Commissie verschillende rollen speelt: ze is tegelijkertijd verslaggever, scheidsrechter en supporter (Westerman 2010, p. 901). Verslaggever naar de samenleving als geheel ('uw belastinggeld wordt goed besteed: juristen verrichten nuttig werk en leveren kwaliteit'), scheidsrechter voor de onderzoeksfondsen ('in Tilburg wordt uw geld het best besteed') en supporter van het rechtswetenschappelijk onderzoek bij de universiteitsbesturen ('maak van uw rechtenfaculteiten geen onderwijsfabrieken'). Wat daarvan zij, het oordeel van de

1 Het rapport, dat in juli 2010 verscheen, besloeg voor de meeste faculteiten de jaren 2003-2008. Tot de te visiteren programma's behoorde ook de criminologie, maar die discipline blijft hier buiten beschouwing. Het rapport van de vorige evaluatiecommissie (Ten Kate) werd besproken door Tijssen (2003).

2 Tot een vergelijkbare conclusie kwam de vorige visitatiecommissie; zij sprak van 'een behoorlijk wetenschappelijk niveau (...) met enkele uitschieters naar boven' (Commissie Ten Kate 2002, p. 21).

3 Hoewel er 'afvallers' zijn, mocht uit de mondelinge toelichting bij de presentatie worden afgeleid dat programma's die op een schaal van 1 tot 5 lager dan '4' scoorden, in de ogen van de Commissie een onvoldoende verdienden. 
commissie is positief; over het rechtswetenschappelijk onderzoek in Nederland hoeft niemand zich zorgen te maken. Of toch wel? Want minstens zo interessant zijn de meer algemene beschouwingen van de commissie. Wat zij tegenkwam, omschrijft zij als 'een discipline in transitie'. Daarmee houdt zij de juristen een spiegel voor. ${ }^{4}$ Kwaliteit \& diversiteit is daarmee een rijk rapport dat leidend moet zijn voor universitaire en facultaire bestuurders.

\section{Rechtsgeleerdheid of rechtswetenschap?}

Het onderzoek van juristen wordt traditioneel 'rechtsgeleerdheid' ('legal scholarship') genoemd, niet 'rechtswetenschap' ('legal science'). De Commissie kiest niettemin voor dat laatste, rechtswetenschap. In de Engelse samenvatting van het rapport luidt het kort en krachtig (Commissie Koers 2009, p. 5, 15, 30): 'Netherlands legal scholarship has now become a true "science of the law".' Scholarship en science kennen beide een eerbiedwaardige geschiedenis. Is de eerste meer verbonden met de geesteswetenschappen, de tweede is de aanduiding voor het medische en natuurwetenschappelijke onderzoek, inclusief een deel van de sociale wetenschappen. Het woord rechtswetenschap wordt in ons land steeds vaker gebruikt. ${ }^{5}$ Wat men ook van deze, uiteindelijk ook semantische, keuze voor 'rechtswetenschap' mag vinden - in het Duits luidt de overkoepelende term 'Rechtswissenschaft', in het Frans 'sciences juridiques' - belangrijk is de onderliggende beweging: de juridische wetenschap behoort tot het geheel der wetenschappen. De keuze voor rechtswetenschap lijkt vooral tactisch ingegeven. In de interne en externe bekostiging van wetenschappelijk onderzoek leggen de meer normatieve wetenschappen het af tegen de harde(re) natuurwetenschappen, maar er is meer aan de hand dan woordkeus alleen kan oplossen. De rechtswetenschap lijkt in het grotere geheel van academie en samenleving een nog tamelijk onbekende wetenschap. Het is voor velen onvoldoende duidelijk wat de bijdrage van de rechtswetenschap aan de vooruitgang van onze samenleving is. 'Ik dacht dat jullie een soort universitaire notarissen waren', zei me een hoogleraar biologie verbaasd na mijn diesoratie over rechtswetenschap of rechtsgeleerdheid.

In de Verenigde Staten en in het Verenigd Koninkrijk valt die onduidelijke positie ook te zien in de bredere context van de plaats van de rechtenfaculteiten binnen universiteiten. Veelzeggend is de observatie van de Amerikaan Samuelson, dat in de VS de relatie tussen universiteiten en hun law schools vaak niet veel meer behelst dan een gemeenschappelijke postcode (Samuelson 1975, p. 258). En al was de vaststelling in 1918 van de befaamde Amerikaanse socioloog en econoom Thorstein Veblen (1918, p. 155) nog dat in point of substantial merit the law

4 De discussie speelt al langer: vgl. Stolker 2003, De Geest 2004. Zie recenter Smits 2009, met veel nationale en internationale literatuur, waarnaar hier kortheidshalve zij verwezen. Onlangs verscheen nog Van Hoecke 2011. Ik kon het boek niet meer in deze publicatie betrekken.

5 Vgl. bijvoorbeeld Wissink \& Westerman 2008; Van Klink 2010, de oratie waarmee Van Klink zijn leeropdracht in de Methoden en technieken van recht en rechtswetenschap aan de VU Amsterdam aanvaardde. 
school belongs in de modern university no more than a school of fencing or dancing, ${ }^{6}$ een kleine zestig jaar later kon een commentator nog steeds over de juristen aan universiteiten spreken als 'a very inferior set of people who mainly teach because they cannot make a success at the bar. ${ }^{7}$ Voor het VK zou het niet veel anders zijn. De Britse hoogleraar Bradney schreef (1998, p. 80): 'Historically, the law school has contributed little to the main body of the university except to provide large numbers of highly qualified students taught very cheaply.'

De onduidelijke positie van de juristen in het orkest der wetenschappen lijkt inderdaad historische verklaringen te hebben. Voor ons land wijst Otterspeer in een vergelijking tussen geneeskunde en recht op het beslissende belang van de negentiende eeuw, een periode waarin de juristen nu eens als meer 'wetenschappelijk' werden gezien, en dan weer als uitgesproken beroepsvoorbereidend. Uiteindelijk vond er een consolidatie plaats 'van een klemtoon op algemeen vormend, encyclopedisch onderwijs naar een (curriculum) dat veel meer de praktische toepassing van de wetenschap in het vizier heeft' (Otterspeer 2005, p. 92). Terwijl de juristen zich 'concentreerden op traditie, stand en stage' kozen de medici ervoor 'zich via moderniteit, universiteit en wetenschap te profileren' (Otterspeer 2005, p. 91). Het onderwijscurriculum ging zich meer en meer richten op het recht van de nationale staat, in een periode waarin de natuurwetenschappen en de geneeskunde juist internationaler werden. Wat bovendien het aanzien van juristen niet verhoogde was dat zij in 1840 als enigen de mogelijkheid kregen van het promoveren op stellingen in plaats van op een dissertatie, een 'voorrecht' dat ze behielden tot 1921. De dissertatie bestond meestal uit een paar bladzijden stellingen of uit hooguit vaardig uitgevoerd compileerwerk, ook wel 'een omslachtig soort visitekaartje' genoemd (Otterspeer 2005, p. 94). De rechtsgeleerdheid en de medische- en natuurwetenschappen lijken elkaar in die periode te hebben gekruist. De rechtsgeleerdheid ontwikkelde zich in sterk praktijkgerichte onderwijscurricula, nationaal georiënteerd - niet gemakkelijk inhakend op de versnelling en de internationalisering die de natuurwetenschappen doormaakten. Een vergelijkbare ontwikkeling zag men ook in Engeland, waar rechtenfaculteiten pas laat volledig deel gingen uitmaken van de academie, ${ }^{8}$ en in de VS waar law nog steeds als een professional discipline wordt gezien en niet of veel minder als een academic discipline.

Na de oorlog kreeg het onderscheid tussen de 'harde' en de 'zachte' wetenschappen een nieuwe dynamiek. De Britse schrijver C.P. Snow (1959) hield een invloedrijke rede onder de titel The Two Cultures. Hij wees als een van de eersten op de kloof tussen de geesteswetenschappen en de natuurwetenschappen. Vooral van de laatste zouden antwoorden te verwachten zijn op de grote vragen van de

6 Veblen is een nog steeds bekende socioloog en econoom, en auteur van het bekende boek The Theory of the Leisure Class (1899).

7 Geciteerd in een boek dat Anthony Bradney vervolgens schreef (Bradney 2003, p. 3). Het boek geeft een mooi inzicht in de ontwikkelingen en emoties in het Verenigd Koninkrijk.

8 Namelijk (waarschijnlijk) in 1826, binnen University College London (Baker 1977, p.7). Het doceren van het recht is van veel oudere datum, zie nader Bradney 2000. 
wereld; Snow dacht eind jaren vijftig vooral aan de problematiek van de arme landen. Zijn centrale stelling - kortweg: de samenleving heeft meer aan de sciences dan aan de geesteswetenschappen - heeft, behalve dat ze leidde tot veel ergernis bij de geesteswetenschappers, een nog veel belangrijker effect gehad. Dat laat de Amerikaan Jerome Kagan zien, ontwikkelingspsycholoog aan Harvard. In 'Revisiting Snow' wijst hij erop dat sindsdien de natuurwetenschappen en het bètamedische onderzoek er daadwerkelijk in geslaagd zijn op die grote maatschappelijke vragen aan te haken, met de miljoenen vragende infrastructuur die daarbij hoort (Kagan 2010). Wij zouden nu van de 'Grand Challenges' spreken. Het geld kwam aanvankelijk rechtstreeks van de nationale overheden; de universiteiten pasten hun financiering daarop aan (Kagan 2010, p. vii, ix):

'It did not take long for deans and provosts to appreciate that their physicists, chemists, and biologists were bringing large amounts of overhead monies to their institutions, and they felt an obligation to reciprocate the kindness by allowing them more relaxed teaching responsibilities and a bit more respect. Predictably, many natural scientists interpreted their new status as justly earned, and a few began to display some arrogance in their pronouncements. (...) The asymmetry in the largesse available to natural scientists and humanists, created status differentials that eroded collegiality and provoked defensive strategies by the two less advantaged cultures [humanities and social sciences - CS]'.

Kagan beschrijft vervolgens een ontwikkeling binnen de sociale wetenschappen waarbij een deel van de onderzoekers 'rushed to join the natural scientists' (2010, p. vii, ix):

'The scholars, however, who had chosen philosophy, literature, or history, took a more severe beating because they were not privy to the generous grants that brought many millions of dollars to their campuses.'

Juristen behoren tot die groep van scholars die er in de universitaire verdeelmodellen - in de woorden van de Commissie Koers - 'bekaaid' van afkomen (Commissie Koers 2009, p. 55, 56). Ook zij waarschuwt nadrukkelijk voor dat scenario (p. 61 e.v.). Waar de sociale wetenschappen de afgelopen decennia terrein hebben gewonnen, lijkt de juridische discipline achter te blijven.

Eerder heb ik al proberen aan te tonen dat de juristen zelf, ook op het vaste land van Europa, aan deze beeldvorming hebben bijdragen door voor hun onderzoek steeds uitzonderingsposities te bepleiten. ${ }^{9}$ Ontwikkelingen in de andere wetenschappen werden soms al te gemakkelijk en met enig snobisme terzijde geschoven; onderlinge samenwerking en solidariteit waren er ondertussen maar

9 Dat was de achtergrond van mijn publicaties uit 2003 en 2005. Zie over die aparte positie nader Bix 2003. 
zelden. ${ }^{10}$ In dat alles lijkt nu een kentering te zijn gekomen en de bevindingen van de Commissie staan in dát teken: een discipline in transitie. Tegelijkertijd geeft de verbazing van de bioloog ('universitaire notarissen') te denken: dat zelfs binnen de universitaire wereld collega's geen idee hebben wat wij juristen nu eigenlijk doen. ${ }^{11}$ Dat kan overigens heel wel een veel breder probleem van de academie zijn. Wat weten wij eigenlijk werkelijk van elkaar? Collini, in zijn scherpzinnige introductie op Snow, merkt op (1998, p. lvi):

'Outsiders tend to see uniformity in other groups and fine distinctions within their own. From the perspective of a biochemist or electrical engineer the differences between an empirical sociologist and a modern social historian may seem barely perceptible: similarly, to the classicist or the art historian what the different branches of physics share seems far more salient than what divides them. But all these fields or sub-fields have increasingly developed their own concerns, methods, and vocabularies to the point where no one division is obviously more significant than all others. The theoretical economist and the critic of French poetry are as mutually incomprehensible in their professional work as ever "scientists" and "humanists" were supposed to be.'

Mogelijk geldt voor veel meer wetenschapsdisciplines dat zij weinig meer met de naburige wetenschappen delen dan een gemeenschappelijke postcode.

\section{Van nationale naar internationale focus}

De eerste observatie van de Commissie is die van de groeiende internationalisering. Zij stelt vast dat internationalisering een fact of life is geworden voor iedere onderzoeker en voor elke rechtenfaculteit. Er zijn vrijwel geen onderzoeksvragen meer die géén internationale dimensie hebben, al was het maar omdat de hele samenleving geïnternationaliseerd is. ${ }^{12}$ Dat internationalisering een fact of life is, kan gemakkelijk tot de conclusie leiden dat bijvoorbeeld onderzoek naar het internationale strafrecht wetenschappelijker is dan dat naar het nationale strafrecht.

Dat is uiteraard onjuist. Vertrekpunt van alle wetenschappelijk onderzoek is de onderzoeksvraag. Die kan nationaal van aard zijn of (eventueel ook) internationaal. Het voorwerp van studie van veel juristen overal ter wereld wordt gevormd door het recht en door de maatschappelijke vragen van de nationale samenleving: het Nederlandse bestuursrecht, burgerlijk recht of strafrecht, maar steeds in Europese of internationale context. Het begint met de vraag. In die gevallen waar een internationale aanpak voorwaarde is voor een betrouwbare beantwoording van de onderzoeksvraag, is zo'n aanpak, inclusief rechtsvergelijking, uiteraard wel

10 Een aantal malen benadrukt de Commissie het grote belang van samenwerking binnen de discipline (Commissie Koers 2010, p. 57, 62).

11 Zie uitvoeriger het boek van Bradney 2003, met name de introductie.

12 De Commissie benoemt verschillende uitingen van internationalisering (Commissie Koers 2010, p. 30 e.v). 
noodzakelijk. Waar mogelijk, mag dan ook van de onderzoeker worden verwacht dat hij zich blootstelt aan het internationale debat. Door in een andere taal dan Engels, Frans of Duits te schrijven, onttrekt hij zich aan dat debat (Stolker 2004, 2005). ${ }^{13}$

Het zal hard gaan met de internationalisering van het juridische onderzoek, want vooral in de confrontatie met andere rechtstelsels leert men het eigen recht beter te begrijpen. Die ontwikkeling zal ook voor de organisatie van het onderzoek gevolgen hebben. Ze zal leiden tot schaalvergroting en grotere onderzoeksgroepen. Dat heeft niet alleen te maken met het belang van rechtsvergelijkend onderzoek, maar ook met de tendens naar specialisatie (die men in alle wetenschappen ziet) en met de ambitie om meer multidisciplinair en empirisch onderzoek te doen. Zo kunnen bijvoorbeeld afdelingen privaatrecht, met doorgaans niet veel meer dan vijfentwintig onderzoekers (die bovendien een omvangrijke onderwijstaak hebben), niet langer het hele privaatrecht op wetenschappelijk niveau beoefenen. Daarnaast zou samenwerking met onderzoekers uit andere wetenschapsdomeinen ook nog vragen om een multidisciplinaire aanvulling op de groep. Schaalvergroting lijkt dan onvermijdelijk. ${ }^{14}$ Daar komt nog bij dat internationalisering het juridische onderzoek competitiever zal maken. Ook juristen zullen steeds afhankelijker worden van Europa; dat vraagt een sterkere organisatie.

Om die reden is het rapport van de Commissie Veerman (2010) zo ingrijpend. Die commissie concludeerde dat het huidige bestel van hoger onderwijs en onderzoek niet toekomstbestendig is. Haar advies is om een "krachtige impuls te geven aan de kwaliteit en diversiteit' - toevallig ook de titel van het rapport van de Commissie Koers - van het Nederlandse hoger onderwijs en onderzoek. Het uitgangspunt is dat de kwaliteit van het hogeronderwijs en onderzoek over de volle breedte omhoog moet. Om dat te kunnen realiseren pleit de Commissie Veerman voor een drievoudige differentiatie: in de structuur van het stelsel, in de profielen van instellingen en in het onderwijsaanbod. In de woorden van de Commissie (2010, p. 41):

'Daarmee kiest (zij) er doelbewust niet voor om in Nederland één of twee instellingen te stimuleren de absolute top te bereiken, hoe wenselijk dat wellicht ook kan zijn. In plaats van te streven naar één of twee topuniversiteiten krijgen vakgebieden en opleidingen binnen universiteiten de kans te excelleren. Instellingen moeten daar gericht op sturen door prioriteiten te stellen én samenwerking met elkaar te zoeken.'

De aanbeveling van 'Veerman' heeft ertoe geleid dat de twaalf, sterk lokale universiteiten nu zoeken naar meer regionale samenwerking. Die ontwikkeling kan - mits goed georganiseerd - tot de grotere onderzoeksgroepen leiden die met

14 Zie voor de rijkdom van het juridische empirisch onderzoek Cane \& Kritzer 2010. 
meer specialisatie en diepgang hogere toppen bereiken. Hoewel deze ontwikkeling van samenwerking primair gedreven wordt door de belangen van de medische en natuurwetenschappen, kunnen ook rechtenfaculteiten van deze ontwikkeling profiteren. Dat geldt voor de grote rechtsgebieden, maar ook voor bedreigde rechtsgebieden als rechtsgeschiedenis en internationaal privaatrecht. Opeenvolgende visitatiecommissies vroegen aandacht voor de toekomst van juist die gebieden (Commissie Koers 2009, p. 59) ${ }^{15}$

\section{Van mono- naar multi- en interdisciplinair}

Het rapport van de Commissie laat zien dat het juridische onderzoek nog sterk monodisciplinair van karakter is. Weliswaar ontstond er in de jaren tachtig en negentig van de vorige eeuw een nauwe samenwerking van de rechtswetenschap met bijvoorbeeld de bestuurskunde, de economie en de politicologie, maar echt doorgezet heeft deze ontwikkeling zich niet. In het privaatrecht, strafrecht, bestuursrecht of internationaal recht blijven onderzoekers toch vooral actief binnen het eigen rechtsgebied. Laat staan dat de stap wordt gezet naar samenwerking met andere wetenschappelijke disciplines. Dat is niet alleen een Nederlands fenomeen. Een Brits rapport - Law in the Real World - stelt vast (Genn, Partington \& Wheeler 2006, p. 29; Genn 2007, p. 4):

'There is little disagreement that law schools have historically been dominated by theoretical and text based doctrinal research. This is reflected in the research skills taught at undergraduate level. Most law courses do not incorporate empirical legal research material into their teaching programmes. Thus undergraduates have few opportunities to read empirical legal research, much less develop skills in empirical data collection. Even in areas like family law and welfare law, where evidence about social context is arguably vital to understanding the profile of cases that arise, there are few texts that build in empirical material.'

Deze ontwikkeling kan gemakkelijk leiden tot self-replication. Zittende monodisciplinaire wetenschappers zullen niet zo snel onderzoekers uit andere disciplines aannemen. En voor henzelf geldt dat 'once in post, the mid-career possibilities for legal academics interested in developing empirical research skills are limited' (Genn, Partington \& Wheeler 2006, p. 29; Genn 2007, p. 4). Het gevolg is dat het belang van het samenwerken met andere wetenschapsdisciplines vooral met de mond wordt beleden: onderzoek wordt al heel gauw 'multidisciplinair' genoemd. Daarom wil de Commissie de termen 'multi'- en 'interdisciplinair' reserveren voor de samenwerking tussen de rechtswetenschap en andere wetenschapsdisciplines. Multidisciplinair onderzoek is dan dat onderzoek waarin wetenschappers uit verschillende disciplines samenwerken, elk met gebruikmaking van hun eigen methoden en technieken. Interdisciplinair onderzoek onderscheidt zich daarvan 
doordat het zich richt op een vraagstelling die verschillende disciplines beslaat, waarin gebruik wordt gemaakt van een gezamenlijk ontwikkelde set methoden en technieken. Onderzoek tussen rechtsgebieden, zoals tussen het strafrecht en het fiscale recht, zou niet langer multi- of interdisciplinair moeten heten (Commissie Koers 2009, p. 32). De Commissie sluit hiermee aan op de gangbare wetenschappelijke terminologie.

Er is uiteraard een goede verklaring voor de dominantie van de monodisciplinaire aanpak: de traditionele rechtswetenschap is minder gericht op de bestudering van het recht als sociaal of cultureel verschijnsel (het externe perspectief) dan op de rechtspraktijk: het recht als normatieve ordening (een intern perspectief). Beide perspectieven gaan niet goed samen. Daar komt de verantwoordelijkheid van rechtenfaculteiten voor de opleiding van praktijkjuristen nog bij. Ook daar komt regelmatig de vraag aan de orde of er niet meer aandacht zou moeten zijn voor andere disciplines. Vooropgesteld zij dat rechtenfaculteiten zowel in het onderwijs als in het onderzoek een lange traditie kennen met betrekking tot de rechtsgeschiedenis, de rechtsfilosofie, en inmiddels ook de rechtseconomie. Het is vooral de verbinding met de sociale wetenschappen die aandacht verdient. Het rapport van de Commissie laat zien dat systematisch multi- en interdisciplinair onderzoek met de sociale wetenschappen in Nederland aan een aantal faculteiten op niveau plaatsvindt. Een voorbeeld bieden de onderzoeksprogramma's van de rechtenfaculteit van de Universiteit van Tilburg, met instituten voor bijvoorbeeld Victimologie, Recht en economie, en Law, technology and society, maar er zijn ook andere. De Rijksuniversiteit Groningen lijkt daarentegen wat terug te komen op een tamelijk sterk interdisciplinair profiel (van recht, bestuurskunde en politicologie), terwijl de privaatrechtjuristen van de Erasmus Universiteit Rotterdam juist heel nadrukkelijk voor een behavioral approach kiezen. De Tilburgse onderzoeksprogramma's en het Rotterdamse privaatrechtelijke programma worden door de Commissie hoog gewaardeerd. ${ }^{16}$ Ook faculteiten met een substantiële criminologische groep hebben extra kansen.

\section{Van vanzelfsprekendheid naar methodologie}

Een volgende belangrijke ontwikkeling die de Commissie signaleert betreft de onderzoeksmethodologie. ${ }^{17}$ Die blijft bij de juristen nogal impliciet. Zij lijken elkaar daarin wel te verstaan, maar waar andere onderzoekers in beeld komen, bijvoorbeeld bij de verdeling van externe onderzoeksgelden, rijzen er methodologische vragen waarmee juristen het moeilijk hebben. ${ }^{18}$ Rechtenopleidingen kennen dan ook geen vak 'methoden en technieken van wetenschappelijk onderzoek',

16 De nogal eens gehoorde klacht dat de leden van evaluatiecommissies in een wereld leven die allang voorbij is, wordt op dit punt in elk geval gelogenstraft; zij het dat Pauline Westerman (2010, p. 901), ook voor deze evaluatiecommissie refereert aan het hoge aantal 'pensionado's'.

17 De Commissie geeft zelf het goede voorbeeld door haar rapport van een uitvoerige beschrijving van werkwijze en methodologie te voorzien (Commissie Koers 2009, p. 17).

18 Zie uitvoerig Smith 2009. 
zoals de sociale wetenschappen dat wel kennen. Promovendi beginnen met hun onderzoek zoals hun promotoren ooit begonnen; als een vorm van tacit knowledge. Als onze methode al wordt geduid, dan gebeurt dat veelal met aanduidingen als 'klassiek', 'doctrinair' of 'juridisch dogmatisch'. ${ }^{19}$ Voor deze methodologische onuitgesprokenheid is de afgelopen jaren in Nederland veel aandacht geweest, zowel in de wetenschappelijke literatuur ${ }^{20}$ als in (en voor) het rechtenonderwijs. ${ }^{21}$ Sommige faculteiten, zoals die van Tilburg en de VU, benoemden hoogleraren voor de theorie van de methodologie. En nu dan verschijnt het nieuwe tijdschrift Recht en Methode.

De rechtswetenschap is met haar deels normatieve karakter misschien wel de moeilijkste wetenschap die er is (Wendt 2009). Voor bijvoorbeeld het internationaal recht heeft de Fin Koskenniemi de uitdagingen prachtig uitgewerkt (Koskenniemi 2006, p. 562, 600). Toch wordt de vraag naar een explicitering van de onderzoeksmethode niet alleen aan juristen gesteld, maar ook aan bijvoorbeeld historici, filosofen, theologen en literatuurwetenschappers. Het gaat dan vaak om onderzoek waarin de persoon van de onderzoeker met zijn maatschappelijke en ethische opvattingen in de onderzoeksvraag en in de conclusies kan doorklinken. De oplossing ligt niet in het blind kopiëren van natuurwetenschappelijke methoden naar de rechtswetenschap. Hesselink komt terecht tot die conclusie (2009, p. 44$):^{22}$

'Legal scholars should not try, out of theory guilt, to imitate the natural sciences. (...) There is no epistemic distinction between the kind of knowledge produced by the natural sciences and that by legal scholars, nor is there such a distinction between traditional legal scholarship (from the internal perspective) on the one hand, and the external perspectives on the law such as the economic analysis of law, on the other, or between the study of national and more international parts of the law like European law. Any existing differences relate, in particular, to the research questions and the different agreed methods and practices for answering these questions.'

Het ligt wel voor de hand nauwkeurig kennis te nemen van elkaars methoden van wetenschapsbeoefening; een expliciete, gedeelde methode is bovendien een absolute voorwaarde voor geslaagde onderzoeksprogrammering (zie hierna).

Van de methodendiscussie moet worden onderscheiden de daaraan voorafgaande vraag naar de zorgvuldigheid van alle wetenschappelijk onderzoek. Smith e.a. stellen vast dat pas bij tekortkomingen - de probleemstelling is onduidelijk, relevant

19 Trotter Hardy 1991, en recenter Tijssen 2009, p. 68, 120, 143.

20 Zie bijv. Smits 2009, p. 93 e.v. en het preadvies van Smith 2009, p. 202, met een nawoord van Soeteman 2009, p. 226.

21 Een voorbeeld van het laatste is een mooie Utrechtse tweetalige publicatie, Curry-Sumner e.a. 2010. Voorts in dit nummer Curry-Sumner \& Van der Schaaf 2011, p. 64 e.v. en Smits 2009, p. 189. 
bronnenmateriaal is niet geraadpleegd, de analyse is onzorgvuldig, de redenering inconsistent, de afweging eenzijdig - de contouren van goed rechtswetenschappelijk onderzoek zichtbaar worden (Smith e.a. 2008). Het gaat dan inderdaad niet om de methode, maar om de eisen die aan álle wetenschappelijk onderzoek mogen worden gesteld, zoals het op kritische wijze formuleren van een onderzoeksvraag, het op kritische en integere wijze verzamelen, ordenen, analyseren en interpreteren van de bronnen (wetgeving, rechtspraak en literatuur), met waakzaamheid voor de normatieve aspecten van zowel de onderzoeksvraag als van de resultaten van het onderzoek. ${ }^{23}$ Want een belangrijk verschil met de natuurwetenschappen is dat de rechtswetenschap naast een descriptieve wetenschap ook een normatieve discipline is, op zoek naar beter recht met het oog op een betere samenleving. Nieuwenhuis spreekt van het recht als 'Hinkelspel rond de boom der kennis van goed en kwaad' (Nieuwenhuis 2006, p. 5). ${ }^{24}$ In die laatste verschijningsvorm spreken de feiten niet voor zichzelf, maar vergt het onderzoek bijvoorbeeld ook overtuigingskracht. De rechtswetenschap wordt daarom ook wel een 'argumentatieve discipline' genoemd (Dworkin 1986).

Vranken (2010, p. 94) gaat daar ver in. Schrijvend over juridische proefschriften stelt hij:

'De auteur moet de lezer meenemen in een argumentatielijn, hij moet diens scepsis overwinnen, en de twijfel, de vragen en kritiek die gaandeweg opkomen, wegnemen. Soms is daarvoor een grondige bespreking van arresten en literatuur nodig, maar even belangrijk is het om hoofd- en bijzaken goed te onderscheiden, geen zijpaden te bewandelen, zich te beperken tot de kern van de boodschap die men wil uitdragen, en geen twintig argumenten aanvoeren als er daarvan maar drie of vier echt sterk zijn. Het is goed de lezer iets te raden, aan te vullen, of te wensen over te laten.'

Wetenschap als boodschap? Wetenschap als roman ('de lezer')? Geen wetenschappelijke discipline moet het hebben van argumenten die niet 'echt sterk' zijn, maar deze passage laat glashelder de precaire balans zien die de rechtswetenschap zo mooi én zo lastig maakt.

'Leesbaarheid' is een andere voorwaarde die Vranken benoemt. Ze hangt samen met overtuigingskracht. In zijn voorwoord op de rede van C.P. Snow ziet ook Collini (1998, p. lix, lx) hier een verschil tussen 'the two cultures':

'Accuracy, clarity, economy are certainly required in the presentation of results, but arranging one's findings in intelligible form is regarded by many research scientists as something of a chore. When scientists admire the "elegance" of a theory or finding - and it is worth remembering that they do so frequently - it is usually its conceptual or mathematical neatness or the economy of its explanatory principles they are admiring. Elegance of style tends

23 Vgl. Curry-Sumner e.a. 2010, p. 37 e.v.

24 Zie voorts de bijdrage van Van Dunné 2010. 
not to be cultivated or prized as a professional ideal, though individual scientists may cherish it. But in many humanities subjects, not only may the most creative thinking be done in the very process of writing, but the manner in which a book or article is written is itself the chief embodiment of the level of understanding that has been reached. In this respect, work in the humanities tends to be both more individual and less susceptible or paraphrase or synthetic re-statement.'

Maar ook hier weer die balans: zijn we voldoende kritisch als ons onderzoek inderdaad 'less susceptible of paraphrase' (Collini) is? Wim Voermans twijfelt: hij wijst op de vaak verscholen ideologische bias in ons onderzoek. ${ }^{25}$

\section{Van individueel onderzoek naar programmering}

De Commissie moest zich op basis van het protocol op onderzoeksprogramma's concentreren. Zij kwam drie soorten programma's tegen: kleine, gericht op een concreet resultaat, programma's als kader voor onderzoek naar een concreet omschreven onderwerp of vraagstelling, en programma's als kader voor langetermijnonderzoek naar een bepaald algemeen thema. ${ }^{26}$ De Commissie dringt aan op een heldere terminologie (Commissie Koers 2009, p. 43). Met het oog op toekomstige visitaties is het daarom goed om de term 'onderzoeksprogramma's' te reserveren voor langetermijnonderzoek met een reikwijdte van minimaal vijf jaren, en met ruimte voor meer dan één gezamenlijke onderzoeksvraag. Die onderzoeksvragen moeten inhoudelijk, en dus meer dan alleen thematisch, samenhangen. Het evaluatieprotocol spreekt vrij ruim van een 'coherent set of research activities having a common mission and being the work of a group of people who generally work together on a daily basis'. Bovendien is er, zoals opgemerkt, voor een programma een gedeelde methode nodig: onderzoek naar de rule of law door rechtsfilosofen met hegeliaanse of platoonse inspiratie samen met rechtssociologen met

Ik citeer collega Voermans in een commentaar op een eerdere versie van dit artikel omdat zijn observatie zo belangrijk is. 'Wat ik me altijd al heb afgevraagd is waarom juristen (ik) in hun benadering zo weinig geïnteresseerd zijn in samenhangende relaties (patronen, oorzaak-gevolgrelaties). Wat je bijvoorbeeld van normen van een grondwet (wereldwijd) zou willen weten is of en hoe ze bijdragen aan welvaart, langdurige vrede onder de bevolking, legitimiteit van overheidshandelen (bijvoorbeeld blijkend uit afname van conflicten, buitenparlementaire strijd, etc.). Van sommige van mijn collega's krijg ik dan te horen dat dat of niet te onderzoeken is, of (en dat is veel erger) als er een keer een relatie wordt vastgesteld (die ene verontrustende bijvoorbeeld dat een nagenoeg ijzeren relatie bestaat tussen een minimum pro capita inkomen en de kans op duurzame democratie), je daar vooral geen geloof aan moet hechten. Dat heeft volgens mij sterk te maken met een traditie in ons vak (een mooi vak overigens) waarin recht wordt gezien als geloof, of toch tenminste als missie. Een missie gericht op het vinden en verbreiden van rechtvaardigheid, rechtsbeginselen, mensenrechten, democratie. Zeg maar recht als beschavingsideaal in ontwikkeling. Die vaak verscholen ideologische verankering is een belangrijk obstakel voor bepaalde vormen van onderzoek. En het is bij veel discussies de wetenschappelijkheid van het recht en de rechtswetenschap ook de "elephant in the room".' Zie ook het hiervóór aangehaalde artikel van Koskenniemi (2006), met een vergelijkbare observatie. 
sterke foucauldiaanse inspiratie levert geen goed onderzoek op; zij verstaan elkaar niet.

De noodzaak te komen tot programmering betekent dat faculteiten en onderzoeksgroepen keuzes moeten maken. Het ligt dan meer voor de hand om de vraag te stellen 'waar kunnen wij samen heel goed in zijn?', dan de vraag 'waar kan elk van ons heel goed in zijn?'. Met onderzoeksprogrammering hebben juristen het lang moeilijk gehad, en eigenlijk is dat nog steeds zo. Zij vraagt om een cultuuromslag en dat kost tijd. Zo vereist onderzoeksprogrammering elkaar regelmatig zien, een wil tot samenwerken en daarmee een bereidheid tot gezamenlijke besluitvorming ('wat gaan we doen?', en meer nog: 'wat gaan we niet langer doen?'). De resultaten ervan kunnen een dwingend karakter krijgen ('met jouw onderzoek gaan we stoppen'). Programmering wordt daarom wel gevoeld als een schending van de academische vrijheid.

Tot het begin van deze eeuw werd vaak lippendienst aan de onderzoeksprogrammering bewezen, ofschoon er ook tal van voorbeelden waren van succesvolle programmering, bijvoorbeeld via de onderzoekscholen (Ius Commune, Mensenrechten, ondernemingsrecht in Nijmegen), of rond bepaalde uitgaven (de 'losbladigen' bijvoorbeeld), of zelfs hele instituten, zoals ooit het Leidse 'Sturing en samenleving', nadien 'Recht en Beleid', met veel multi- en interdisciplinair onderzoek. ${ }^{27}$

Programmering betekent ten slotte ook: heel goede mensen naar elders laten gaan: waar kan een student, promovendus of postdoc excelleren? De sterrenkunde in Nederland werd groot en internationaal vermaard door het systematisch scouten van jong talent door alle hoogleraren gezamenlijk, ook als dit betekende dat een jonge onderzoeker van de ene groep naar de andere moest verhuizen omdat daar zijn of haar talenten beter tot hun recht zouden komen. De Commissie geeft in algemene zin aan hoe belangrijk het is dat rechtenfaculteiten gaan samenwerken.

Onderzoeksvisitaties zijn een belangrijke driver van programmering van onderzoek. Het is voor een visitatiecommissie onmogelijk om kennis te nemen van duizenden losse wetenschappelijke publicaties van negen faculteiten over een periode van zes jaren. Om iets zinnigs te kunnen zeggen over de kwaliteit van een rechtenfaculteit is een gestructureerd aanbod van onderzoeksvragen en onderzoeksresultaten daarom onontbeerlijk. Een tweede driver is het toegenomen belang van externe onderzoeksfinanciering, nationaal en Europees. Naarmate de omvang van de subsidies toeneemt, zal steeds nauwkeuriger worden gekeken naar de kwaliteiten en de reputatie van een gehele groep. Een derde driver ligt in

27 Zo had bijvoorbeeld het privaatrecht in Leiden in de jaren tachtig en negentig een sterk profiel op het aansprakelijkheidsrecht en het contractenrecht. Verbindend waren de losbladige commentaren waarvan de zittende hoogleraren de hoofdredactie voerden. Aldus ontstond als vanzelf een vorm van impliciete programmering. Nadien verdween dat weer enigszins; met onderzoeksprogramma's als 'Vraagstukken van vermogensrecht' werd gepoogd bredere thema's te bestrijken, maar echte programmering was dat niet. Uit andere faculteiten zijn vergelijkbare voorbeelden te geven. 
de opdracht van de Commissie Veerman om te profileren en om versnippering van publieke middelen te voorkomen. Steeds vaker wordt universiteiten gevraagd waarin ze de Europese of zelfs de wereldtop zijn of willen zijn. Die vraag geldt ook het juridische onderzoek. Wat antwoordt een Leidse of Groningse rector magnificus als hem door de minister wordt gevraagd waarin zijn of haar rechtenfaculteit tot de landelijke of zelfs Europese top behoort? Niet geloofwaardig is het antwoord: 'in eigenlijk alles'. Het rapport van de Commissie laat voor het juridische onderzoek weliswaar enige profilering zien, maar met uitzondering van de sterk multi- en interdisciplinaire benadering die Tilburg heeft gekozen en de thematische benadering van Nijmegen (ondernemingsrecht) is het lastig om werkelijke profielen te zien. De meeste faculteiten doen nog steeds zo veel mogelijk 'alles'. Nederlandse universiteiten, inclusief de rechtenfaculteiten, lijken daarom veel op elkaar (Smits 2009, p. 188) ${ }^{28}$ De nauwe band tussen onderwijs en onderzoek leidt er begrijpelijkerwijs toe dat faculteiten zo breed mogelijk willen opereren. Maar werkelijke keuzes worden zo ontlopen en daarmee mist de discipline als geheel kansen op werkelijk internationale topkwaliteit.

Deze vaststelling geldt niet alleen rechtenfaculteiten, maar voor een groot deel van het Nederlandse onderzoekslandschap: een meer dan acceptabele hoogvlakte, maar slechts weinig internationale toppen. Universiteiten hebben daarom intern gekozen voor profileringsgebieden waarin de toppen van het lokale universitaire wetenschappelijk onderzoek meer kans krijgen. Dat werkt in hoge mate sturend: want wie in de externe financiering niet meedoet, heeft altijd nog de zogenoemde eerste geldstroom; maar wie ook binnen zijn eigen universiteit niet meedoet aan profilering en programmering, loopt het gevaar met uitsluitend onderwijs achter te blijven. De Commissie wijst er wel op dat door dit teveel aan universitair beleid onderzoeksprogramma's juist een deel van hun focus en coherentie zijn kwijtgeraakt. Ze vraagt zich af of dat opweegt tegen de beoogde meerwaarde (Commissie Koers 2009, p. 57). ${ }^{29}$ Daar zit - zeker voor de brede universiteiten - inderdaad een lastig probleem; zo zou het Leidse universiteitsbestuur het liefst een focusgebied 'Law and Governance' zien.

\section{De promovendi: van een piramide naar een twee-lagenstructuur}

Wetenschapsdisciplines die onvoldoende investeren in talentvolle masterstudenten, promovendi en postdocs zijn als wetenschap uiteindelijk ten dode opgeschreven. De gebruikelijke vorm van een onderzoeksgroep is de piramide. De rechtswetenschap kampt op het punt van de samenstelling van haar onderzoeksgroepen met problemen. Promovendi zijn er nog wel, maar na de promotie is het lastig hen als universitair docent vast te houden; de praktijk trekt. De Commissie stelt vast dat voor sommige gebieden een two layer structure van vooral hoogleraren en promovendi is ontstaan. Ze maakt zich zorgen over het ontbreken van postdocs;

29 Zie ook Report from Horizon 2020 (2011). 
ze geeft de discipline ter overweging mee minder middelen te reserveren voor promovendi, en juist meer voor postdocs en senioronderzoekers, 'zodat de tweelagen-structuur weer meer op een piramide gaat lijken' (Commissie Koers 2009, p. 36).

De Commissie ziet nog een tweede zorgelijke ontwikkeling. Nu promotieonderzoek steeds meer in competitie verworven wordt, worden de ingediende onderzoeksvoorstellen zó complex en ambitieus dat de vraag rijst of dat onderzoek nog wel door een promovendus kan worden uitgevoerd. Alsof, schrijft de Commissie met bewuste overdrijving, 'de jongste bediende het moeilijkste werk moet opknappen' (Commissie Koers 2009, p. 34). Het aantal uitvallers is, vergeleken met de natuurwetenschappen, (dan ook?) hoog.

Er is nog iets wat daaraan bijdraagt. De rechtsgeleerdheid houdt, samen met de geesteswetenschappen, nog tamelijk hardnekkig vast aan het promoveren op monografieën (Commissie Koers 2009, p. 57). Het belang van een brede studie - de monografie - mag niet worden onderschat. Maar in de meeste andere wetenschapsdomeinen is het promoveren op gepubliceerde of geaccepteerde artikelen de regel. Er zijn immers serieuze nadelen: promoveren op een boek is in de regel aanzienlijk arbeidsintensiever dan promoveren op een bundeling van artikelen en vergt een voortdurend updaten. Een tweede nadeel is dat de auteur van een monografie langer nodig heeft om van de omgang met zijn wetenschappelijke peers te profiteren dan wie vrijwel vanaf het begin artikelen publiceert. Een derde nadeel is dat het schrijven van een boek als één lange sprint is, en daardoor moeilijker vol te houden. Wie op artikelen promoveert, legt afzonderlijke etappes af en kan steeds weer moed vatten door terug te kijken op wat is bereikt.

Met uitzondering van de rol van promovendi en postdocs geeft de Commissie wat minder aandacht aan de samenstelling van een onderzoeksgroep of van een hele faculteit als geheel. ${ }^{30}$ In een rapport van de OECD over demografische ontwikkelingen in het hoger onderwijs wordt erop gewezen dat universiteiten meer en meer gaan lijken op (kortweg) het bedrijfsleven (Enders \& Musselin 2008, p. 146):

'The growing need to profile individual universities and to commit faculties to the mission of the institution, calls for a new organizational identity among the faculties. Teamwork within and across organizational sub units is growing, while the "group" becomes an important unit to measure success alongside the individual scholar. (...) [T] he university is no longer unlike other organisations, or at least it is less unlike.'

Er lijkt alle reden voor HR-afdelingen van universiteiten en faculteiten om, met verstand natuurlijk, ook over de grenzen heen naar andere typen organisaties te kijken. Dat doet de academie al als het gaat om de financiën, vastgoed of facilitei-

30 Wel verwacht zij veel van de 'jongere hoogleraren': '[v]an hen mag veel worden verwacht als zij de ruimte en de middelen krijgen om hun stempel op het onderzoek te drukken' (Commissie Koers 2009, p. 52, 62). 
ten, maar op het punt van personeelsbeleid lijkt ze nog achter te blijven, niet alleen op het bedrijfsleven maar ook op bijvoorbeeld ministeries.

Weer een ander aspect van personeelsbeleid raakt de kérn van het academisch bedrijf: het bevorderen van creativiteit. De samenstelling van een groep beïnvloedt de mate van wetenschappelijke creativiteit ervan. De Commissie dringt erop aan nieuwe en jonge hoogleraren 'de ruimte te geven hun plannen en ambities waar te maken' (Commissie Koers 2009, p. 58). De veronderstelling is dat diversiteit een impuls geeft aan creativiteit: jong én oud, hemelbestormers én zwoegers in het vooronder, mannen én vrouwen, nationaal én internationaal, diversiteit van disciplines. Eerder heb ik daarnaar enig literatuuronderzoek gedaan (Stolker 2006). Het onderwerp heeft sociologische en psychologische kanten. Van de Amerikaanse wetenschapssocioloog Merton komt de fraaie term 'serendipitous micro-environment', een omgeving waarin creativiteit gedijt (Merton \& Barber 2004, 230 e.v.). De wetenschapssociologie bestudeert de sociale context waarin onderzoek en onderwijs plaatsvinden. In combinatie met de wetenschapspsychologie ontstaat een fascinerende manier van kijken naar onderzoeksgroepen. De Amerikaanse psycholoog Simonton (2004) onderzocht vier bepalende voorwaarden voor creativiteit: 'chance', 'logic', 'genius', en 'Zeitgeist' (de eerste in alle diversiteit van betekenissen die dat woord heeft, van geluk, toeval, kans, mogelijkheid, serendipiteit, en zo meer). Het gaat, aldus Simonton, niet om niets (2004, p. 180):

'(...) if I had to identify the single most critical topic for research, it would probably concern the characteristics of the creative scientist. More specifically, we need to know more about how various developmental and dispositional factors determine the type of creativity displayed by any individual.'

Het is een thema dat voor universiteiten steeds belangrijker zal worden. De typische omgeving waarin rechtenfaculteiten opereren, en waarin de rechtspraktijk sterk 'trekt', maakt het soms lastig om werkelijk te bouwen aan een diverse groep. Anderzijds biedt juist die mobiliteit ook het voordeel van steeds weer nieuwe kansen.

\section{Van eerste naar andere geldstromen; valorisatie}

Ook de wijze waarop het juridische onderzoek wordt gefinancierd draagt bij aan het beeld van een 'discipline in transitie'. Van oudsher ontvangen juridische faculteiten hun geld van de universiteit. De grondslag van de financiering van het onderzoek is vooral het onderwijsvolume. Via een vaste opslag op het onderwijs leveren meer studenten ook meer onderzoeksgeld op. Deze koppeling tussen onderwijs en onderzoek spreekt evenwel niet vanzelf: kwaliteit in het onderwijs garandeert niet automatisch kwaliteit in het onderzoek. Vandaar het toenemende belang van de zogenaamde 'tweede geldstroom' (nationale en EU-onderzoeksfondsen) en de 'derde geldstroom' (contractonderzoek). Toch is de eerste geld- 
stroom nog dominant; over alle faculteiten gezamenlijk gemeten maakt NWO/EU niet meer dan zes procent uit van de totale onderzoeksfinanciering (Commissie Koers 2009, p. 36) Gemiddeld bedraagt de verhouding onderwijs-onderzoek voor juristen aan Nederlands universiteiten 70-30 (Commissie Koers 2009, p. 391).

Rechtenfaculteiten presteren naar verhouding redelijk als het gaat om het binnenhalen van extern gefinancierd promotieonderzoek. Aanzienlijk slechter doen ze het in de persoonsgerichte subsidies (Vernieuwingsimpuls, Spinoza, European Grants). De verschillen zijn hier niet alleen groot met de natuurwetenschappen, maar ook met gedragswetenschappen als economie en psychologie, en de geesteswetenschappen. De Commissie veronderstelt dat het niet zo zal zijn dat juristen 'geen goede ideeën' zouden hebben, of geen goede voorstellen zouden kunnen schrijven. Een belangrijke oorzaak ligt in het carrièreverloop. Het dominante carrièreverloop is voor veel rechtsgebieden nog steeds dat de promovendus na de promotie voor een aantal jaren de rechtspraktijk in gaat om daarna eventueel terug te keren naar de academie. Als gevolg daarvan valt er een groot gat in publicatielijn. Omdat het aantal publicaties een belangrijke parameter voor kwaliteit is, ondervinden juist juristen daarvan ernstig nadeel. ${ }^{31}$ Een ander erkend probleem is het nog steeds overwegend Nederlandstalige karakter van ons onderzoek; mijn veronderstelling is dat de promovendus die zijn proefschrift nu nog in het Nederlands gaat schrijven, daarmee een wetenschappelijke carrière via de tweede geldstroom (NWO/EU) heeft opgegeven.

Valorisatie is de term die wordt gebruikt voor het proces dat wetenschappelijke kennis omzet naar commercieel haalbare producten en diensten. De vraag naar valorisatie wordt steeds vaker gesteld; onze tijd is er niet een van zuiver wetenschappelijk onderzoek. ${ }^{32}$ Snow verwachtte het heil vooral van de natuurwetenschappen; dat lijkt ook voor de Nederlandse regering het dominante idee. In de zogenoemde Innovatieagenda die in 2008 door de verantwoordelijke ministeries en brancheorganisaties is getekend wordt opgemerkt (Valorisatieagenda 2008):

'De (...) agenda heeft betrekking op de benutting van kennis in alle domeinen, maar is gebaseerd op ervaringen met de valorisatie van medisch, technisch en bètaonderzoek en met het R\&D intensieve bedrijfsleven. Dit komt omdat op deze terreinen de meeste initiatieven zijn ontstaan. De ondertekenaars zullen ook valorisatie in het alfa- en gammadomein, de kunsten en het interdisciplinair onderzoek stimuleren.'

31 'Waarom scoort juridisch onderzoek zo slecht bij NWO?', Bijlage 1 bij Commissie Voorbereiding Onderzoeksbeoordeling Rechtsgeleerdheid 2005.

32 Zie www.valorisatie.nu, Den Haag: Science Alliance. Zie voorts het evenwichtige rapport van STW, Rathenau Instituut en Technopolis, Waardevol. Indicatoren voor valorisatie, Utrecht: 21 juli 2011, dat een opzet biedt voor de samenstelling van zogenoemde 'valorisatiekaarten'. Die zouden op termijn een middel kunnen vormen om valorisatie-inspanningen en resultaten van verschillende instellingen met elkaar te vergelijken. Een model voor de geesteswetenschappen is al uitgewerkt. 
Deze vraag naar het maatschappelijk nut is juist voor juristen heel goed te beantwoorden. Bijzonder aan de rechtswetenschap is dat haar resultaten niet voorbehouden blijven aan de kleine groep van collega-wetenschappers, maar nagenoeg een-op-een worden gedeeld met praktijkjuristen (Posner 2002, p. 1314). ${ }^{33}$ Nederland kent nauwelijks tijdschriften die uitsluitend door rechtswetenschappers worden gelezen. De Fin Koskenniemi (2006, p. 617) ziet het verschil tussen 'academics' en 'practitioners' als een 'contentious distinction': ze beoefenen beiden het recht - alleen de context verschilt. Dat ligt anders voor de meeste andere wetenschappen. Zo zijn praktijkpsychologen of huisartsen nauwelijks meer in staat de 'eigen' wetenschappelijke tijdschriften te lezen.

Naast de wetenschappelijke publicaties is de niet-wetenschappelijke vakpublicatie belangrijk. Vakpublicaties zijn bij uitstek gericht op de disseminatie van wetenschappelijk onderzoek onder praktijkjuristen. Ze zijn daarmee belangrijke instrumenten van valorisatie van wetenschappelijk onderzoek.

Hierna in paragraaf 11 komt nog ter sprake de keuze voor zogenoemde 'topsectoren' (Nederland) en 'grand challenges' (Europa). Daarin gaat zeer veel onderzoeksgeld om. De rechtswetenschap mag niet achterblijven (Commissie Koers 2009, p. 60-61). Haar kansen zijn goed beschouwd groot: waar valorisatie in het domein van het bètamedische en natuurwetenschappelijke onderzoek vele jaren kan duren, bedraagt de doorlooptijd in de rechtswetenschap vaak slechts vier dagen. Het artikel dat op vrijdag in het Nederlands Juristenblad verschijnt, wordt op zaterdag gelezen en is op maandag in een pleitnota verwerkt.

Ten slotte, dat juristen achterblijven in geldstromen speciaal voor het onderzoek is geen Nederlands verschijnsel alleen. In de Duitse Exzellenzinitiative bleven in de eerste ronde de sociale en juridische wetenschappen en de geesteswetenschappen ernstig achter (Hartmann 2006, p. 447). Met dit ingrijpende programma proberen de Duitse regering en de deelstaten met een totaalbedrag van ruim twee miljard euro profiel te brengen in het Duitse wetenschappelijk onderzoek. Onder de gehonoreerde voorstellen vond ik er slechts twee waarin juristen - althans - participeerden: 'Die Herausbildung normativer Ordnungen' (Frankfurt) en 'Religion und Politik in den Kulturen der Vormoderne und der Moderne' (Münster).

\section{$9 \quad$ Van laissez faire naar beleid en sturing}

De Commissie stelt vast dat het rechtswetenschappelijk onderzoek niet langer iets is waarin individuele onderzoekers zichzelf maar moeten zien te redden, maar een zaak waarvoor de organisatie - universiteit, faculteit, instituten en programmaleiders - medeverantwoordelijkheid draagt. Ze stelt daarnaast vast dat er veel tot stand is gebracht. Zo zouden inmiddels vrijwel alle onderzoekers het werken in gezamenlijke onderzoeksprogramma's accepteren en wordt er geen tijd en energie meer verspild aan 'nutteloze achterhoedegevechten'. Een tweede vaststel- 
ling is dat alle faculteiten goedwerkende kwaliteitszorgsystemen hebben: onderzoekers en programma's worden met enige regelmaat intern tegen het licht gehouden. Voor individuele onderzoekers lijkt een opbrengst van drie wetenschappelijke publicaties per jaar een geaccepteerd minimum te zijn - de Commissie heeft wel haar aarzelingen bij aantallen - maar de lat kan anders worden gelegd (Commissie Koers 2009, p. 54-55). Onderzoekers die onder de maat zijn worden daarop aangesproken; programma's die te weinig kwaliteit opleveren kunnen worden beëindigd.

Uit het rapport van de Commissie mag worden opgemaakt dat faculteiten hier en daar strenger kunnen zijn in de classificatie van wat wetenschappelijke en wat vakpublicaties zijn. Naar aanleiding van een vorige visitatie beval een door decanen ingestelde adviescommissie aan de rechtswetenschappelijke discipline aan om, met respect voor haar eigenheid, zoveel mogelijk aansluiting te zoeken bij wat op dit punt in andere wetenschappen gangbaar is. Zij drong erop aan niet te coulant te zijn (Commissie Voorbereiding Onderzoeksbeoordeling Rechtsgeleerdheid 2005, p. 26-27). ${ }^{34}$ Op een internationale conferentie die in 2004 in Den Haag door NWO werd georganiseerd drong ook de Britse rechtswetenschapper John Bell daarop aan (2004):

'The key criteria for the quality of the content of research are that it must contribute significantly to the existing knowledge or understanding of the subject. This has two components. The research must offer a new insight. In law, it is not sufficient that the information is new, since new laws or judicial decisions occur all the time. There must be a new explanation or way of organising the material. The work must also advance scholarship. The best research will shape the field - it will be a point of reference for subsequent research and not simply providing useful summaries for future scholars. In terms of method, law is an eclectic subject. The key is that the method is appropriate to the research. By its use, the research can contribute new insights. It is not sufficient that the method is novel. It must yield results that constitute a contribution to knowledge, and so demonstrate its value.'

Het nieuwe dat een publicatie moet bieden hoeft volgens de Commissie niet per se betrekking te hebben op de uitkomst van het onderzoek of van de bereikte conclusie. Het kan evenzeer betrekking hebben op het onderwerp, de invalshoek, op de ordening, de argumentatie en de onderzoeksmethode(n). Daarnaast moet er toch altijd sprake zijn van een duidelijke probleemstelling of vraagstelling, moet er diepgang en grondigheid in het gebruik van bronnen zijn, moeten de opbouw en de argumentatie zorgvuldig en controleerbaar zijn en moeten de gehanteerde onderzoeksmethoden worden geëxpliciteerd en verantwoord (Bell 2004). Als deze criteria het minimum zijn, dan zit het verschil tussen een goede en een uitstekende publicatie, volgens de Commissie, in de mate waarin aan deze criteria wordt voldaan en daarnaast in zaken als participatie in het internationale debat, 
de mate van werkelijke multi- of interdisciplinariteit, het belang van een rechtsvergelijkende component, de originaliteit of complexiteit van de gebruikte onderzoeksmethode of de bijdrage aan theorievorming (Commissie Koers 2009, p. 28).

\section{Van een vrijblijvende naar een meer objectieve publicatiecultuur}

Pas als faculteiten en onderzoeksgroepen consequent de maatstaven hanteren die bepalen of een publicatie als 'wetenschappelijk' mag gelden - alle zijn in een protocol netjes uitgewerkt (Commissie Voorbereiding Onderzoeksbeoordeling Rechtsgeleerdheid 2005, par. 6) - is een vergelijking tussen onderzoekers, programma's en faculteiten mogelijk. Maar uiteindelijk mag de controle op zo'n juiste classificatie niet berusten bij een individuele programmaleider of een vice-decaan voor het onderzoek. Het moeten de tijdschriften zijn die schiften. Dat gebeurt nu onvoldoende of is onvoldoende transparant. De rechtswetenschap kent daarom een publicatiecultuur die lastig valt te beoordelen (Stolker 2005). De Commissie noemt als 'het meest belangrijke zwakke punt' dat er binnen de discipline geen algemeen gedeelde opvatting bestaat over wetenschappelijke kwaliteit op grond waarvan onderzoeksresultaten beoordeeld kunnen worden (Commissie Koers 2009, p. 54, 29). Een separaat 'wetenschappelijk gedeelte' kennen de meeste tijdschriften nog niet (Commissie Koers 2009, p. 48).

Het argument dat niet te doen vanwege het gevaar dat praktijkjuristen van het wetenschappelijk gedeelte snel zullen 'doorbladeren' naar het praktijkdeel ${ }^{35}$ mag geen reden zijn de diffuse situatie te laten voortbestaan. Ook de vrees voor een kloof tussen rechtswetenschap en praktijk mag geen argument zijn om geen helder onderscheid te maken (Klijnsma, Van Leeuwen \& Stein 2010). Het zal vast zo zijn dat sommige wetenschappelijke publicaties zich meer zullen richten op pure wetenschappers dan op praktijkjuristen, zoals de meer inter- en multidisciplinaire law and...-publicaties, zoals rechtsgeschiedenis, rechtseconomie, rechtssociologie en rechtspsychologie. Maar zelfs dan mag men niet te snel denken aan een puur wetenschappelijke kring van afnemers van onderzoek. Het mag zo zijn dat de gemiddelde advocaat of notaris minder belangstelling zal hebben voor een rechtspsychologische benadering van het privaatrecht, dat geldt bijvoorbeeld weer niet voor wetgevingsjuristen of rechters, voor wie bijvoorbeeld dat gedragsperspectief juist van groot belang is. ${ }^{36}$

Een ander probleem is dat tijdschriften in aanvulling op de kwalitatieve beoordeling door de redactie slechts bij uitzondering een aanvullende externe peer review kennen. Bovendien kent de juridische discipline geen formele classificatie van tijdschriften, zoals de A-, B- en C-tijdschriften in de economie. Een bijkomend probleem is dat de rechtswetenschap op dit moment niet de mogelijkheid kent om citaties enigszins betrouwbaar te tellen. 
Externe peer review, ranking van tijdschriften, het tellen van citaties en het meten van impact zijn even zovele instrumenten om de kwaliteit van onderzoeksgroepen en van individuele wetenschappers te meten. Het ontbreken ervan maakt het voor bestuurders van universiteiten, voor nationale en internationale onderzoeksfondsen, en voor evaluatiecommissies lastig om te oordelen over de kwaliteit van onderzoeksgroepen en individuen. In tijden van serieuze bezuinigingen op onderwijs en onderzoek is die situatie ronduit risicovol. De Commissie Koers stelt vast dat van haar werd verwacht dat zij 'met terugwerkende kracht' een vorm van peer review uitvoert voor in elk geval de kernpublicaties, terwijl in andere disciplines juist dit soort publicaties 'al lang en breed peer review (en dan meestal double blind) achter de rug hebben (Commissie Koers 2009, p. 47). Zij roept de Nederlandse rechtendecanen op om snel werk te maken van een publicatiecultuur die meer houvast biedt. In een eerste inventarisatie die onder wetenschappers werd gehouden kort voor de Commissie haar werkzaamheden aanving, bleek dat vrijwel alle Nederlandse juridische tijdschriften naar hun inzicht als wetenschappelijke tijdschriften zouden moeten worden aangemerkt. Een bijdrage aan de oplossing van het probleem leverde deze exercitie daarmee niet. De decanen willen het daarom anders aanpakken. ${ }^{37}$ Van alle Nederlandse tijdschriften die op de lijst van wetenschappelijke tijdschriften willen komen, wordt externe peer review verwacht (al dan niet blind of double blind). Publicaties in tijdschriften die daaraan niet willen meewerken, moeten door de faculteiten niet langer als wetenschappelijke publicaties worden aangemerkt, wat ertoe zou leiden dat onderzoekers die tijdschriften gaan mijden. Voorts wordt van de tijdschriftredacties verwacht dat zij, in geval zij zowel wetenschappelijke als vakpublicaties willen opnemen, aangeven of het om het een of het ander gaat. Vanzelfsprekend moet dóórschieten worden voorkomen; Vranken en Van Gestel wijzen daarop in een diepgravende analyse van het beoordelen van rechtswetenschappelijke publicaties. ${ }^{38}$

Maar de tijd dringt. In Europa loopt het Verenigd Koninkrijk voorop. Dat maakt op dit moment de overstap van de Research Assessment Exercise (RAE) naar het nieuwe Research Excellence Framework (REF). De uitkomsten van de REF moeten de nationale onderzoeksfondsen houvast bieden bij het verdelen van onderzoeksgelden, de belastingbetaler verantwoording bieden en universiteitsbesturen inzicht geven in de relatieve positie van hun onderzoeksgroepen. Het valt daarbij op dat in aanvulling op het meten van de wetenschappelijke impact de maatschappelijke impact (societal impact) belangrijker is geworden. Discussie over de vraag of de maatschappelijke invloed van wetenschappelijk onderzoek is te meten is er

37 Het rapport van de naar haar voorzitter genoemde Commissie Du Perron wordt binnenkort verwacht en zal een overzichtelijke samenvatting bevatten van het werk van twee eerdere commissies (in de wandeling de commissies 'Stolker' en 'Smits'). 
genoeg (Bekhradnia 2009), ${ }^{39}$ maar de ontwikkeling lijkt niet meer te stoppen. De REF richt zich op output, impact en environment:

'In forming their overall quality judgements, the panels will assess three distinct elements of each submission - outputs, impact and environment against the following generic criteria:

a. Outputs: The sub-panels will assess the quality of submitted research outputs in terms of their "originality, significance and rigour", with reference to international research quality standards. This element will carry a weighting of 65 per cent in the overall outcome awarded to each submission.

b. Impact: The sub-panels will assess the "reach and significance" of impacts on the economy, society and/or culture that were underpinned by excellent research conducted in the submitted unit, as well as the submitted unit's approach to enabling impact from its research. This element will carry a weighting of 20 per cent.

c. Environment: The sub-panels will assess the research environment in terms of its "vitality and sustainability", including its contribution to the vitality and sustainability of the wider discipline or research base. This element will carry a weighting of 15 per cent. ${ }^{30}$

Dus niet alleen: wie publiceert het meest in de beste tijdschriften of wie wordt het best geciteerd?, maar ook voor 20\%: wie is maatschappelijk invloedrijk?. Het komende jaar zullen alle Britse universiteiten, ook de rechtenfaculteiten, met casestudies en aan de hand van een streng protocol die maatschappelijke impact aannemelijk moeten maken. Rechtenfaculteiten zullen dus op twee fronten actief moeten zijn: de wetenschappelijke impact en de maatschappelijke.

Ook al zijn er bezwaren aan te voeren tegen bibliometrics of scientometrics, tegen het uitrekenen van impact, wetenschappelijk en maatschappelijk, ook in andere landen zal de rechtswetenschap ermee te maken krijgen, al was het maar als gevolg van de Europese onderzoeksprogrammering. Komt de discipline niet zelf met een min of meer acceptabel systeem, dan verzinnen anderen wel iets, zoals het tellen van downloads of citaten via SSRN, Google scholar, Scopus, of via de universitaire repositories. In haar zoeken staat de discipline niet alleen. Onze buren aan de ene kant, de sociale wetenschappen, zijn meer en meer vertrouwd geraakt met het (Engelstalige) Web of Science. Met de rechtswetenschap meer vergelijkbare problemen hebben onze geesteswetenschappelijke buren aan de andere

39 Interessant is het onderzoek van de Britse Fiona Cownie (2004) die onderzoekers interviewde over hun ervaringen met de RAE. De opvattingen varieerden, maar één conclusie was wel dat 'there appears to be little doubt that its effects on the discipline of law have been to increase the rate of its move away from the legal profession (...) towards the centre of academy' (2004, p. 200). Eerder in haar boek sprak ook zij, vooral in verband met de methode, van een 'discipline in transition'.

40 Website van de Higher Education Foundation Council for England: www.hefce.ac.uk (25-9-2011), alwaar alle informatie is te vinden. 
kant. Voor deze discipline heeft de Commissie Algra onlangs een conceptsysteem ontwikkeld dat een zorgvuldige mix zou moeten zijn van verschillende kwaliteitsindicatoren, met een dominante rol voor de peers, met disciplinespecifieke of contextspecifieke indicatoren, en met ruimte voor het toevoegen van indicatoren die kunnen voortvloeien uit een toenemende digitalisering van de wetenschaps- en publicatiepraktijk. Deze commissie hoopt een flexibel en maximaal eenvoudig systeem te hebben ontwikkeld (Commissie Kwaliteitsindicatoren Geesteswetenschappen 2011). ${ }^{41}$ Het systeem wordt de komende jaren uitgeprobeerd op het onderzoek van twee Nederlandse geesteswetenschappelijke instituten. Het zou goed zijn als ook onze discipline met dit systeem zou willen mee-experimenteren.

\section{Profilering en de 'grand challenges'}

Het gaat - ten slotte - niet alleen om het tegengaan van verspilling van publieke middelen en om het bevorderen van hoogwaardig onderzoek. Boven op de geschetste facultaire programmering en de universitaire profileringen zien we een derde profileringslaag ontstaan. Europa laat zich in de aanloop naar haar al genoemde 2020-strategie (ERA Expert Group 2008) niet imponeren door tien of twintig profileringsgebieden per Europese universiteit, laat staan door zestig onderzoeksprogramma's binnen één landelijke discipline. Europa wil in het wetenschappelijk onderzoek de Europese grand challenges terugzien:

'Europe is confronted with a number of complex interrelated socio-economic challenges - such as creating and maintaining robust growth and jobs, tackling inequalities and migration flows, finding solution for the ageing society, enhancing the security of its citizens and of the economy, as well as the uptake of security solutions by potential users, and managing globalisation which require an in-depth understanding and comparable pan-European evidence for improved policy-making.

The uncertainties ahead linked to ageing, globalisation, insecurity, intercultural encounters, individualism, the penetration of technologies in daily lives, the ecological turn and the weakened capacities of political systems to respond to expectations as well as natural and man-made threats in particular, clearly point to major social, economic and political changes for Europe. The scientific challenge is thus for Europe to understand how and why these changes have taken place, how societies are likely to react and develop policies, technologies and related capabilities that can sustain the key objectives of inclusiveness, innovation and security, and how policy learning across Europe (and beyond when necessary) can improve. ${ }^{42}$

41 De Commissie stond onder voorzitterschap van de Utrechtse hoogleraar in de Geschiedenis van de filosofie Keimpe Algra.

42 Het citaat komt uit de eerste schets voor het 2020-programma: 'Inclusive, Innovative and Secure Societies', Report from Horizon 2020 (2011). Het 2020-programma zal in 2014 FP7 vervangen. 
De Europese Commissie stelt voor de komende jaren een bedrag van tachtig (!) miljard euro voor, specifiek voor onderzoek en innovatie (EU budget 2014-2020 2011). Eenzelfde beweging naar een maatschappelijke thematisering ziet men in de Nederlandse politiek, waar in zogeheten 'topsectoren' wordt gedacht: life sciences, hightechmaterialen en -systemen, agro-food, water, energie, tuinbouw, chemie, creatieve industrie en logistiek (Brief van de minister van Economische Zaken 2011). Binnen deze topsectoren moet worden samengewerkt tussen kennisinstellingen, bedrijfsleven en overheid, de zogeheten 'gouden driehoek'. De Strategische Agenda (2011, p. 47) van het kabinet bouwt daarop voort: ${ }^{43}$

'Verdere profilering in het onderzoekslandschap is ook nodig met het oog op een nog grotere bijdrage van de wetenschap aan onze samenleving en de vragen waarvoor zij staat. De grand challenges zijn in Europa in toenemende mate een belangrijke aanvliegroute voor het definiëren van grootschalige onderzoeks- en innovatieprogramma's. Van belang is dat de Nederlandse kenniswereld hierop goed inspeelt en maximaal kan profiteren van de (financiële) kansen die Europa biedt. Dit vraagt om profilering op onderzoeksdomeinen die van belang zijn voor maatschappelijke uitdagingen zoals energie- en waterschaarste, voedselvoorziening, verouderende samenlevingen, volksgezondheid, pandemieën, voedselveiligheid en de opwarming van de aarde. Daarbij zijn niet alleen de bèta- en technische disciplines in beeld, ook van de sociale en de geesteswetenschappen wordt een stevige bijdrage verwacht. De economische topsectoren leveren overigens ook een belangrijke bijdrage aan deze maatschappelijke thema's. De grand challenges vormen voor de economische topsectoren ook kansen om geld mee te verdienen. Maatschappelijke uitdagingen liggen niet altijd in het verlengde van de topsectorenaanpak. Daarom is in het profileringsproces van de kennisinstellingen ook aandacht nodig voor (veelal multidisciplinair) onderzoek dat nodig is om ook aan die maatschappelijke uitdagingen het hoofd te kunnen bieden.'

Grand challenges. Men hoort C.P. Snow vijftig jaar na dato: welke wetenschap draagt werkelijk bij aan de oplossing van de grote vragen waarvoor Europa en de wereld staan? Het zijn algauw onderwerpen met een sterk technische en bètamedische inslag. Voor rechtenfaculteiten houdt deze ontwikkeling een lastige opdracht in. In het citaat uit de strategische agenda wordt de rechtswetenschap hooguit impliciet ('sociale en de geesteswetenschappen') genoemd. Waar en hoe haken wij in op die grote vragen? Global Justice and Governance is zonder twijfel zo'n grand challenge, die bijvoorbeeld met de oprichting van het The Hague Institute of Global Justice in juni 2011 grootschalig kan worden aangepakt. Maar hoe kan het gewone privaatrecht, bestuursrecht of strafrecht aan dit type van superambities bijdragen? Mijn antwoord zou zijn: dat kan heel goed; we doen het al, maar laat het zien! Rechtvaardigheid, rechtsstaat, ordening, toezicht, beslechting

43 Zie voorts het SER-advies Strategische Agenda Hoger Onderwijs, Onderzoek en Wetenschap, Advies 11/07, april 2011, bijlage bij Kamerstuk 31 288, nr. 194 en opgenomen als bijlage hij het eindrapport 2011. 
van geschillen, veiligheid en grondrechten, consumentenbescherming, maar ook de scheve verdeling tussen arm en rijk die Snow zo bezighield, het zijn willekeurige onderwerpen waarmee juristen zich bezighouden. Ze spelen zeker niet alleen op Europees niveau, maar evenzeer in de stad ('Urbi et orbi'). ${ }^{44}$

Tegelijkertijd zal het werken aan de grote thema's ook het gewone doctrinaire handwerk nodig hebben - normal science. Posner wijst daar terecht op (2009, p. $854-855):{ }^{45}$

'[T] he law schools need legal analysts, not merely as teachers but also as scholars. Doctrinal analysis cannot be left to judges. (...) I would like to see more academic effort devoted to tidying up after judges.'

Ook dat blijft een belangrijke taak van het rechtswetenschappelijk onderzoek, in omvang zonder twijfel de belangrijkste, die we evenwel meer dan nu moeten expliciteren, uitdragen en verbinden met de vragen die samenlevingen op dit moment bezighouden. Ook als de resultaten niet hemelbestormend zijn. Voor het internationaal recht bijvoorbeeld benadrukt Koskenniemi die taak (2006, p. 603): 'Today, it often seems that academic work in the field is justifiable only if it ends up in a proposal of Institutional reform.' Hij heeft gelijk. Het gaat veeleer om een voortdurende stroom van grote en kleine valorisaties, waaruit blijkt dat de nationale en de internationale samenleving niet zonder haar rechtswetenschappers kan.

\section{Slot en conclusie}

De Commissie Koers heeft in haar rijke en inhoudelijke rapport ook naar zichzelf gekeken. Ze geeft aan dat landelijke visitaties op deze manier niet langer mogelijk zijn. Zelfs als faculteiten in staat zouden zijn om werk te maken van een inzichtelijker publicatie- en verantwoordingscultuur blijft het voor één commissie allemaal veel te veel. Het ging in de laatste onderzoeksvisitatie om negen faculteiten, met in totaal zestig onderzoeksprogramma's, met duizenden publicaties. De Commissie verzucht dat het benodigde tijdsbeslag voor emeriti wellicht nog haalbaar is, maar voor personen die nog volop in functie zijn 'eigenlijk een onmogelijke opgave is' (Commissie Koers 2009, p. 50). Bovendien is het voor één evaluatiecommissie nauwelijks meer mogelijk om de volle breedte van het juridische onderzoek inhoudelijk te beoordelen. Dat wordt nog moeilijker als faculteiten zich meer op multi- en interdisciplinair onderzoek gaan richten. De toekomst zal daarom liggen in visitaties van één rechtsgebied (internationaal recht, privaatrecht), of in visitaties van een kleiner aantal faculteiten, maar dan met voorzieningen voor grensoverschrijdend onderzoek, eventueel ook internationaal.

44 Vergelijk bijvoorbeeld SEO Economisch Onderzoek 2009.

45 De gedachtewisseling gaat over de relatie tussen 'judicial work' en 'academic work'. Zie ook Soeteman in zijn bespreking van het proefschrift van Wendt (2010). 
Gelukkig kon de Commissie Koers nog tot het oordeel komen dat het 'goed (gaat) met het juridisch onderzoek in Nederland'. Maar behalve tot de samenleving, de grote onderzoeksfondsen en de colleges van bestuur richt de Commissie zich ook tot de discipline zelf; een discipline in transitie, waar nog veel moet gebeuren. Dat kan gemakkelijk tot ergernis leiden. Want wie zich maar enkele van onze grote juristen voor ogen haalt - voor civilisten: mannen als Meijers en Cleveringa, Scholten en Pitlo, Schoordijk, Hartkamp, Nieuwenhuis en Vranken, en zovele anderen - zal wellicht menen dat deze opdracht ('doe wat!') bijna ongepast is. Meijers' invloed reikt tot ver in Rusland. Daar staat tegenover dat als rechtenfaculteiten in moeilijke financiële tijden en in een steeds meer competitieve en internationale omgeving deel willen blijven uitmaken van de academische gemeenschap, er wel iets moet gebeuren. In elke raad van decanen stelt eenmaal per jaar de rector de vraag: 'Wie dragen wij dit jaar voor een Spinoza voor?'. Het antwoord is niet vanzelfsprekend. Want 'ja, geléérd zijn jullie wel, maar een Spinoza...? Hoe groot is die kans? We hebben trouwens ook een sterrenkundige...'.

Het is meer dan mee-stribbelen alleen. De juristen behoren tot de universitas magistrorum et scholarium; eeuwenlang vormden ze het hart ervan. Daarom: de rechtswetenschap is goed op weg, maar op een aantal punten is haast geboden. Dat geldt vooral de externe oriëntatie, in drievoud: onze wijze van publiceren en de wetenschappelijke kwaliteitszorg die daarbij hoort (peer review, ranking, wetenschappelijke impact), onze thematische profilering (de Europese grand challenges en de nationale topsectoren), en onze maatschappelijke impact ('valorisatie'). Juist in die externe verantwoording en oriëntatie mag de rechtswetenschap de aansluiting op de andere wetenschappen niet verliezen.

\section{Literatuur}

\section{Baker 1977}

J. Baker, 'University College and Legal Education 1826-1976', Current Legal Problems 1977-30, p. 7.

\section{Bekhradnia 2009}

B. Bekhradnia, Proposals for the Research Excellence Framework. A Critique, London: Higher Education Policy Institute, 2009.

\section{Bell 2004}

J.S. Bell, 'Standards of Good Practice in Legal Research: A British Perspective', 2004. Zie (1-9-2011): http://www.nwo.nl/files.nsf/pages/NWOP_66YM8Y/\$file/SaRO_con gres_programma_en_abstracts.pdf.

\section{Bix 2003}

B.H. Bix, 'Law as an Autonomous Discipline', in: The Oxford Handbook of Legal Studies, Oxford: Oxford University Press 2003.

\section{Bradney 1998}

A. Bradney, 'Law as a Parasitic Discipline', Journal of Law and Society 1998, p. 80.

\section{Bradney 2000}

A. Bradney, 'English University Legal Education: Elite Education or Mass Education? Some Preliminary Observations', in: P. Torremans (ed.), Legal Convergence in the Enlarged Europe of the New Millennium, The Hague: Kluwer 2000. 


\section{Bradney 2003}

A. Bradney, Conversations, Choices and Chances. The Liberal Law School in the TwentyFirst Century, Oxford/Portland (Or.): Hart 2003.

Brief van de minister van Economische Zaken 2011

Brief van de minister van Economische Zaken, Landbouw en Innovatie van 4 februari 2011 inzake de hoofdlijnen van het nieuwe bedrijfslevenbeleid, Naar de top, Kamerstukken II 2010/11, 32 637, nr. 1.

Cane \& Kritzer 2010

P. Cane \& H.M. Kritzer (eds.), The Oxford Handbook of Empirical Legal Research, Oxford: Oxford University Press 2010.

Cauffman 2011

C. Cauffman, 'Verwetenschappelijking van het juridisch onderzoek: een garantie voor beter recht?', NTBR 2011-5, p. 211-215.

Collini 1998

Stefan Collini, 'Introduction' in: C.P. Snow, The Two Cultures, Cambridge: Cambridge University Press 1998.

Commissie Koers 2009

Evaluatiecommissie Rechtswetenschappelijk Onderzoek 2009, Kwaliteit \& diversiteit. Rechtswetenschappelijk onderzoek in Nederland (rapport), Amsterdam: Vrije Universiteit Amsterdam 2009.

Commissie Kwaliteitsindicatoren Geesteswetenschappen 2011

Commissie Kwaliteitsindicatoren Geesteswetenschappen, Kwaliteitsindicatoren voor onderzoek in de geesteswetenschappen (interim-rapport), mei 2011.

Commissie Ten Kate 2002

Rapport onderzoeksbeoordeling Rechtsgeleerdheid 1995-2000, VSNU 2002

Commissie Veerman 2010

Commissie Toekomstbestendig Hoger Onderwijs Stelsel, Differentiëren in drievoud, Den Haag, april 2010.

Commissie Voorbereiding Onderzoeksbeoordeling Rechtsgeleerdheid 2005

Commissie Voorbereiding Onderzoeksbeoordeling Rechtsgeleerdheid, Oordelen over rechten, VSNU 2005.

Cownie 2004

Fiona Cownie, Legal Academics - Culture and Identities, Oxford: Hart 2004.

Curry-Sumner e.a. 2010

I. Curry-Sumner, F. Kristen, M. van der Linden-Smith \& J. Tigchelaar, Onderzoeksvaardigheden. Instructie voor juristen, Nijmegen: Ars Aequi Libri 2010.

Curry-Sumner \& Van der Schaaf 2011

I. Curry-Sumner \& M. van der Schaaf, 'The Theory and Practice of Teaching and Guiding Legal Research Skills', Recht en Methode 2011-1, p. 64-84.

Van Dunné 2010

J. van Dunné, 'Het verschijnsel Hans Nieuwenhuis', in: A.G. Castermans, Jac. Hijma, K.J.O. Jansen, P. Memelink, H.J. Snijders \& C.J.J.M. Stolker (red.), Ex Libris Hans Nieuwenhuis, Deventer: Kluwer 2009, p. 56 e.v.

\section{Dworkin 1986}

R. Dworkin, Law's Empire, Cambridge (MA): Harvard University Press 1986.

Enders \& Musselin 2008

Jürgen Enders \& Christine Musselin, 'Back to the Future? The Academic Professions in the 21st Century', in: Higher Education to 2030, Volume 1: Demography, OECD 2008, p. 146. 


\section{ERA Expert Group 2011}

ERA Expert Group, Challenging Europe's Research: Rationales for the European Research Area, DG Research EUR 23326EN, 2008. Zie (1-9-2011): www.ec.europa.eu/ europe2020.

EU budget 2014-2020 2011

EU budget 2014-2020: Investing today for growth tomorrow, IP/11/799, 29 juni 2011.

\section{Gadamer 1975}

H.-G. Gadamer, Wahrheit und Methode, Tübingen: J.C.B. Mohr 1975.

De Geest 2004

G. de Geest, 'Hoe maken we van de rechtswetenschap een volwaardige wetenschap?', NJB 2004, p. 58.

Genn, Partington \& Wheeler 2006

H. Genn, M. Partington \& S. Wheeler, Law in the Real World. Improving Our Understanding of How Law Works (The Nuffield Inquiry on Empirical Legal Research; Final Report and Recommendations), London: The Nuffield Foundation, 2006.

\section{Genn 2007}

H. Genn, 'Law in the Real World: Building Capacity in Empirical Legal Research, The Reporter 2007, p. 4 e.v.

\section{Van Gestel 2009}

Rob van Gestel, 'Wetgeving en wetenschap', AA 2009, p. 30 e.v.

\section{Harnad 2009}

S. Harnad, 'Open access scientometrics and the UK Research Assessment Exercise', Scientometrics 2009-1, p. 147 e.v.

\section{Hartmann 2006}

M. Hartmann, "The "Exzellenzinitiative" (Initiative of Excellency). A Change of Paradigm in German Higher Education Policy’, Zeitschrift für Sozialwissenschaft 2006-4, p. 447 e.v.

\section{Hesselink 2009}

Martijn W. Hesselink, 'A European Legal Science? On European Private Law and Scientific Method', European Law Journal 2009-1, p. 44.

\section{Van Hoecke 2011}

M. van Hoecke (ed.), Methodologies of Legal Research. Which Kind of Method of What Kind of Discipline?, Oxford and Portland (Or.): Hart 2011.

\section{Kagan 2010}

J. Kagan, The Three Cultures. Natural Sciences, Social Sciences, and the Humanities in de 21st Century, Cambridge: Cambridge University Press 2010.

\section{Klijnsma, Van Leeuwen \& Stein 2010}

Josse Klijnsma, Dirk van Leeuwen \& Daniël Stein, 'Beter kunnen we het niet maken, wel makkelijker', AA 2010, p. 150 e.v.

\section{Van Klink 2010}

B.M.J. van Klink, Rechtsvormen. Autonomie van recht en rechtswetenschap, Den Haag: Boom Juridische uitgevers 2010.

\section{Koskenniemi 2006}

M. Koskenniemi, From Apology to Utopia. The Structure of International Legal Argument, Cambridge: Cambridge University Press 2006.

\section{Merton \& Barber 2004}

R.K. Merton \& E. Barber, The Travels and Adventures of Serendipity. A Study in Sociological Semantics and the Sociology of Science, Princeton: Princeton University Press 2004. 
Muller e.a. 2011

S. Muller, S. Zouridis, M. Frishman \& L. Kistemaker (eds.), The Law of the Future and the Future of Law, Oslo: Torkel Opsahl Academic EPublisher, 2011.

\section{Nieuwenhuis 2006}

J.H. Nieuwenhuis, Vooruit met het recht, Deventer: Kluwer 2006.

\section{Otterspeer 2005}

W. Otterspeer, 'Professionalisering in Nederland in de negentiende eeuw - Een vergelijkend perspectief', in: B. van der Boom \& F.S. Gaastra (red.), Kerk, cultuur en koloniën. Opstellen over Nederland rond 1900, Amsterdam: Balans 2005.

\section{Popper 2003}

K.R. Popper, Conjectures and Refutations. The Growth of Scientific Knowledge, London: Routledge 2003.

\section{Posner 2002}

Richard A. Posner, 'Legal scholarship', Harvard Law Review 2002, p. 1314.

\section{Posner 2009}

Richard A. Posner, 'The State of Legal Scholarship Today: A Comment on Schlag', Georgetown Law Journal 2009, p. 854 e.v.

\section{Report from Horizon 2020}

Report from Horizon 2020 Stakeholder Workshop Inclusive, Innovative and Secure Societies, 2011.

\section{Samuelson 1975}

P. Samuelson, 'The Convergence of the Law School and the University', The American Scholar 1975, p. 258.

\section{Sastry \& Bekhradnia 2006}

T. Sastry \& B. Bekhradnia, Using Metrics to Allocate Research Funds. A Short Evaluation of Alternatives to the Research Assessment Exercise, London: Higher Education Policy Institute 2006.

\section{SEO Economisch Onderzoek 2009}

SEO Economisch Onderzoek, 'Amsterdam, Netherlands: Self-Evaluation Report', OECD Reviews of Higher Education in Regional and City Development, IMHE, 2009. Zie (1-9-2011): http://www.oecd.org/edu/imhe/regionaldevelopment.

\section{SER-advies 2011}

SER-advies Strategische Agenda Hoger Onderwijs, Onderzoek en Wetenschap, Advies 11/07, april 2011, Kamerstukken II 2010/11, bijlage bij Kamerstuk 31 288, nr. 194.

\section{Simonton 2004}

D.K. Simonton, Creativity in Science. Chance, Logic, Genius, and Zeitgeist, Cambridge: Cambridge University Press, 2004.

\section{Smith 2008}

C.E. Smith e.a., 'Criteria voor goed rechtswetenschappelijk onderzoek. De omgekeerde route', NJB 2008, p. 685 e.v.

\section{Smith 2009}

C.E. Smith, 'Het normatieve karakter van de rechtswetenschap: recht als oordeel' (Preadvies Vereniging voor de Wijsbegeerte van het Recht 2009), R\&R 2009, p. 202 e.v.

\section{Smits 2009}

J. Smits, Omstreden rechtswetenschap. Over aard, methode en organisatie van de juridische discipline, Den Haag: Boom Juridische uitgevers 2009.

\section{Smits 2011}

J. Smits, 'European Legal Education, or: how to prepare students for global citizenship?', The Law Teacher 2011-2, p. 178. 


\section{Snow 2009}

C.P. Snow, The Two Cultures, New York: Cambridge University Press (1959), 2009.

\section{Soeteman 2009}

A. Soeteman, 'Wetenschappelijke rechtsgeleerdheid. Commentaar op het preadvies van Carel Smith', $R \& R$ 2009, p. 226 e.v.

\section{Stolker 2003}

C.J.J.M. Stolker, “'Ja geleerd zijn jullie wel!” Over de status van de rechtswetenschap', NJB 2003, p. 766.

\section{Stolker 2004}

C.J.J.M. Stolker, 'Wat maakt een juridisch tijdschrift wetenschappelijk?', NJB 2004, p. 1409 e.v.

\section{Stolker 2005}

C.J.J.M. Stolker, 'Legal Journals: In Pursuit of a more Scientific Approach', European Journal of Legal Education 2005-2, p. 89 e.v.

\section{Stolker 2006}

C.J.J.M. Stolker, 'Vooruitgang in de wetenschap - Vooral toeval of organisatie?', in J.H. Nieuwenhuis \& C.J.J.M. Stolker (red.), Vooruit met het recht. Wat geldt in de rechtswetenschap als vooruitgang? Den Haag: Boom Juridische uitgevers 2006, p. 110 e.v.

\section{Strategische Agenda 2011}

Strategische Agenda Hoger Onderwijs, Onderzoek en Wetenschap van 1 juli 2011, Kwaliteit in verscheidenheid, Den Haag: Ministerie van Onderwijs, Cultuur en Wetenschap, p. 47.

\section{Tijssen 2003}

Hervé Tijssen, 'De beoordeling van rechtswetenschappelijk onderzoek: een vak apart!', NJB 2003, p. 1218 e.v.

\section{Tijssen 2009}

$\mathrm{H}$. Tijssen, De juridische dissertatie onder de loep. De verantwoording van methodologische keuzes in juridische dissertaties (diss. Tilburg), Den Haag: Boom Juridische uitgevers 2009.

\section{Trotter Hardy 1991}

I. Trotter Hardy, 'Why Legal Research Training Is So Bad: A Response to Howland and Lewis', J. Legal Educ. 1991, p. 221.

\section{Trouw 2011}

Trouw 24 juni 2011.

Valorisatieagenda 2008

Valorisatieagenda. Kennis moet circuleren, Innovatieplatform, 3 december 2008.

\section{Veblen 1918}

Thorstein Veblen, The Higher Learning in America, New York: Cosimo Classics 1918.

\section{Vranken 2010}

J.B.M. Vranken, 'Als een arrest niet bevalt, laten wij het gewoon weg', in: A.G. Castermans, Jac. Hijma, K.J.O. Jansen, P. Memelink, H.J. Snijders \& C.J.J.M. Stolker (red.), Ex Libris Hans Nieuwenhuis, Deventer: Kluwer 2010, p. 94 e.v.

\section{Vranken \& Van Gestel 2010}

J.B.M. Vranken \& R.A.J. van Gestel, 'Het dilemma bij de beoordeling van rechtswetenschappelijke publicaties: Vertrouwen is goed, controle niet altijd beter', AA 2010, p. 166 e.v. 


\section{Vranken \& Van Gestel 2011}

J.B.M. Vranken \& R.A.J. van Gestel, 'Assessing Legal Research: Sense and Nonsense of Peer Review versus Bibliometrics and the Need for a European Approach', The German Law Journal 2011, p. 901 e.v.

\section{Wendt 2009}

Ivar Wendt, 'De opgekomen methodenvrees in het rechtswetenschappelijk debat in Nederland. Een voorstel', NJB 2009, p. 786 e.v.

\section{Westerman 2010}

P. Westerman, 'Visitatie in spagaat', AA 2010, p. 901 e.v.

Wissink \& Westerman 2008

M.H. Wissink \& P.C. Westerman. 'Rechtsgeleerdheid als rechtswetenschap', NJB 2008, p. 503 e.v. 